\title{
ENTRE ENSINAR E APRENDER, A TESSITURA DA AULA
}

\author{
Bernardina Maria de Sousa Leal(1)
}

Resumo: As abordagens através das quais a filosofia pode ser trabalhada na prática pedagógica assumem, neste artigo, um papel proeminente. Daí a ênfase na sala de aula, local das possíveis realizações, do confronto entre a antecipação e o acontecimento, do desafio maior da concretização de propostas educativas. Os modos de realização da aula, seus textos, problematizações e questionamentos deles decorrentes, enfim, a investigação filosófica coletiva propiciada pela aula constitui a temática principal deste artigo.

\section{A sala de aula}

A despeito das dimensões físicas, das condições do mobiliário, da disposição das carteiras, da quantidade de pessoas, das instituições que a abrigam, a sala de aula continua a ser um espaço privilegiado de contato humano. É este espaço aglutinador de conhecimentos, sentimentos, atitudes, idéias, palavras e gestos, que nos desafia. Dele emergem diferentes linguagens, possibilidades de contato entre pessoas. Estaremos atentos ao que possa acontecer? Seremos capazes de colocarmo-nos à espreita dos encontros que a sala de aula nos propiciará? Conteremos nosso impulso controlador de antecipar e impossibilitar o novo?

Diante do imediatismo do dia-a-dia escolar (realização de tarefas, organização de recursos, manutenção da rotina, exigências de aperfeiçoamento profissional, luta por melhores condições de trabalho), lembraremo-nos de detalhes que nos fazem gente? Estaremos sensiveis aos apelos que nos são lançados? Conseguiremos percebê-los?

Talvez seja preciso dispormo-nos a rever nossa prática escolar cotidiana.

Redimensionar o saber e o fazer na comunidade estudantil. Investigar nossas relações intersubjetivas. Reorganizar as formas do trabalho pedagógico. Investigar os pressupostos que fundamentam o empreendimento educativo. Questionar conceitos estabelecidos. Perguntarmo-nos sobre infância, adolescência e adultez. Afirmarmos menos. Duvidarmos mais. Elaborarmos novas perguntas.

Trilhar os caminhos por onde leva a filosofia impõe-nos estes e outros tantos desafios. Trata-se de um processo de busca. Não há garantias de alcances. Caminhamos em direção ao que ainda há de desconhecido na sala de aula (aquilo do qual nossos saberes ainda não se apropriaram). Apostamos que algo novo possa emergir de cada encontro, de cada discussão, de cada pensar diferente do nosso, de cada novo questionamento, de cada reflexão. Enfim, de cada aula. Nos interessa o espaço subjetivo da sala de aula. É ele o local do confronto entre a antecipação e o acontecimento. Dele pode emergir o novo. 
Somos gente. Não parece óbvio? Como terá isto se tornado tão óbvio a ponto de não mais o questionarmos? Por que as coisas têm parecido tão evidentes, banais, antecipáveis e até mesmo naturais? Precisamos voltar a estranhá-las. Tratarmos com menos intimidade e descaso o contexto educacional. Espantarmo-nos diante do que ocorre a cada dia nas escolas. Preocuparmo-nos com os espaços educativos transfigurados em salas de aula. Resistirmos à indiferença. É possível que voltemos a nos maravilhar. Quem sabe algo nos surpreenda. Talvez o novo queira se mostrar naquilo que pensamos já conhecer. Pode ser que nosso olhar viciado não nos permita identificá-lo. Será preciso ocuparmo-nos desta outra obviedade: ver.

Ver-se não é algo assim tão simples. Será necessário um cuidadoso exame das atividades a serem desenvolvidas no contexto educacional. Exatamente por não sabermos tudo o que delas poderá advir, precisamos estar atentos. Não se trata de antecipar o que ocorrerá, mas de tornarmo-nos sensíveis aos acontecimentos. Concentrarmo-nos no que fazemos. Dedicarmos nossa atenção uns aos outros. Compartilharmos a admiração pela vida. Talvez devamos retomar a simplicidade das coisas profundas e nos determos em observar o que já existe e pode estar despercebido. Não será necessário fabricar situações que nos levem a pensar. Veremos as mesmas coisas de outro modo.

Mais do que papéis desempenhados, nós, professores e alunos, revelamos em nossos fazeres educativos maneiras de ser e agir impossíveis de se ocultar. São nossas posturas que nos revelam, não os discursos dos quais nos apropriamos. Temos que aprender a conjugar os verbos na forma reflexiva: vermo-nos, pensarmo-nos, questionarmo-nos, investigarmo-nos, duvidarmos de nossas próprias palavras. Nesta busca por nós mesmos, encontraremos muita gente. É desta gente que estamos a falar. Toda esta gente que habita os espaços educativos nos quais transitamos. Às vezes estamos tão apressados, tão indiferentes! Tudo nos parece tão igual! Não nos damos conta...

\section{A disposição para a aula e seus textos}

"Que força interior é essa que transfigura as coisas muitas vezes precárias, arrancando do mutismo da natureza as vozes do sublime?", indaga Régis de Morais (1999, p.12) ao refletir sobre a criação artística. A capacidade, eminentemente humana, de transformar em arte a pedra, a madeira, os sons, as tintas, os corpos e as palavras é admirável. Mas desafiadoramente intrigante é a força impulsionadora que move o artista. O que o levará a criar tanto a partir do que parece tão pouco aos olhares desatentos da maioria de nós? A mesma matéria-prima que provoca em alguns fortes impulsos criadores e os leva a produzir obras de rara beleza é, para muitos, indiferente.

A forma de reagir às coisas, às idéias e aos sentimentos faz muita diferença entre nós. Como nos colocamos diante de tudo o que nos cerca, as possibilidades de correspondência que propiciamos, o quanto estamos dispostos a aprender com pessoas e coisas, demarcará um campo de possíveis realizações. Deste espaço 
delineado poderá emergir o novo. Daquilo que parecia escasso poderá ser retirado o que ainda não havia sido percebido. Ou não.

Nas relações que estabelecemos com os outros (pessoas, coisas, idéias) é que criamos o que ainda não existia para nós. Ao transformarmos traços antes insignificantes de nossas vidas em elementos significantes, estaremos num processo de criação. Esta força não parece estar nas coisas, mas em nós mesmos, no momento em que nos relacionamos com elas. Aprendemos nas relações que criamos, muito mais do que naquilo que pretensamente ensinamos ou nos é ensinado. O outro poderá nos auxiliar a descobrir o que ele já vê e para nós está oculto. Podemos, reciprocamente, mostrar-lhe o que vislumbramos. Podemos, uns nos outros, ver aquilo que não nos aparece nitidamente se estamos sós.

Combinações diversas de elementos novos e antigos, de percepções nossas e de outros, de pensamentos próprios e coletivos se articulam no ato de criação. Os textos se transfiguram, nós também. Mudamos nossas características, aparências e formas. $\mathrm{O}$ inusitado irrompe. Afinal, não trabalhamos os textos para deles obtermos informações, mas transformações. Contudo, para que transformações sejam possíveis, parece necessário a vinculação estreita, senão a própria vivência do mistério encantador que possibilita a criação. Não se trata de possuir um conhecimento sobre o mistério - isto seria uma contradição - mas do envolvimento com o mistério. "Tudo isto exige do poeta (entendido aqui como criador, capaz de poiésis) o fogo misterioso da criação mesma. E do esteta apreciador (capaz de sentir, sensual e sensivelmente) o dom de vibrar às impressões do ato criador e da criação" (ibid, p.15).

Tanto para criar como para apreciar parece haver certo mistério, algo inexplicável. E como estamos acostumados a limitar nossos saberes ao que pode ser explicado, deixamos de criar e apreciar. Não criamos, inibidos pela exigência da explicação antecipada. Também não apreciamos, seja por possuirmos explicações e já estarmos fatigados, seja por não tê-las e nos julgarmos incompetentes sem elas. De qualquer modo, tornamo-nos apáticos. Nada nos passa ou nos move. Não há movências, só rigidez.

Se nas relações que estabelecemos com os textos é que ocorrem transfigurações, temos, então, que colocarmo-nos diante deles visando encontros entre nós e eles. É preciso que estabeleçamos algum tipo de ligação entre a obra (aula expositiva, texto escrito, pintura, fotografia, etc.) e nós mesmos. Não apenas conexões com o conteúdo da obra, mas também com tudo que a obra sugere: suas formas, expressões, representações e entrelinhas. É a riqueza sugestiva da obra que nos evoca outras possibilidades criativas. É como se a obra artística estivesse a desafiar, incessantemente, nosso potencial criador. Daí muitas obras de arte perpassarem o tempo, simultaneamente antigas e atualizadas, resistentes às explicações, conservando seus mistérios.

Mas como dispormo-nos às obras? Esta pergunta ressoa insistentemente, ainda que não pronunciada. Queremos saber como proceder. Precisamos atentar para aquilo que nos fará capazes de criar, apreciar ou mesmo identificar obras de arte. Como 
discernir das obras ou textos, o que possui qualidades propiciadoras de investigações filosóficas? Talvez o próprio termo "disposição" nos diga algo a respeito do que procuramos. Corriqueiramente empregado na língua portuguesa ao final de redações formais, em expressões como "à sua disposição" e "ao seu dispor", esta palavra pode significar uma tendência, inclinação ou propensão. Neste caso tenderíamos ou estaríamos propensos a encontrar algo nos textos. "Disposição" também contém a idéia de intento, propósito ou desígnio. Se assim o admitirmos, teremos o propósito de procurar nos textos questões que venham a problematizá-lo ou a problematizar o que o texto sugere ou ainda a problematizarmo-nos. "Disposição" também pode indicar subordinação ou dependência. Neste sentido, estarmos à disposição dos textos significa nos subordinarmos a eles, deles dependermos. Isto seria o oposto do que normalmente fazemos.

Seja no sentido de inclinação, propósito ou subordinação, o termo "disposição" sugere uma postura, um colocar-se em relação aos textos. Trata-se de uma atitude, um ato ou determinação. Colocarmo-nos onde? Teremos que fazer uma escolha. Se nos colocarmos diante dos textos municiados de estratégias de leituras préconcebidas, dominados por técnicas de compreensão de textos consagradas como garantias de elucidação de sentidos, estaremos fadados a encontrar nada mais do que já foi extraído e nos cansaremos de repetir interpretações já realizadas. No entanto, se nos inclinarmos aos textos não somente para compreendê-los, não exclusivamente para deles retirarmos respostas, mas para colocarmo-nos neles ou incorporá-los em nós de maneira interrogativa, estaremos inaugurando novas formas de ler. Ampliaremos as possibilidades do texto.

Será preciso, no entanto, que não conformemos os textos às nossas modalidades interpretativas. Que não nos interessemos apenas por adaptá-los ao que já sabemos ou intentamos saber. Que não tentemos encaixá-los nos modos de compreensão previamente construídos. Talvez tenhamos que nos sujeitar a eles, nos subordinar, como sugere um dos sentidos do termo "disposição". Mas isto nos parece um forte ultraje. Estamos acostumados a nos colocar diante dos textos como quem já sabe, de antemão, a melhor forma de compreendê-los. Não queremos ser desafiados, confrontados. Não permitimos que nossos modos habituais de compreensão sejam desestabilizados. Temos já previstos e projetados procedimentos destinados a produzir leituras.

E se a leitura for também o lugar da interrupção? Larrosa (2000, p.107) provocanos e leva-nos a pensar na necessidade da ruptura. Romper com o habitual, com o comum, com o já sabido. Provocar rachaduras, abrir frestas, possibilitar o imprevisto. Embora nada disto tenha sido dito, é o que o autor nos sugere com sua pergunta. Ele nos desafia a inquietar a leitura óbvia dos textos. Suas palavras soam como um alerta, um aviso para que estejamos mais atentos, para que tenhamos mais cuidado, para que sejamos menos apressados e arrogantes ao lidarmos com os textos. Uma certa demora, uma espera, um suspense, atenção e escuta, muita cautela, é o que parece nos dizer Larrosa, a meia voz, entre o dito e o não-dito.

\section{Os textos da aula}


Resistir à forma prescritiva e ao tom moralista do discurso pedagógico socialmente estruturado não é fácil. $\mathrm{O}$ ato educativo é um ato de intervenção.

A questão que nos angustia é exatamente esta: como interferir no processo formacional de sujeitos sem a imposição de regras ou normas? Será possível pensar uma formação sem um modelo a formar? Estas e outras questões que dela se desencadeiam dimensionam a dificuldade e o risco de pensar a educação numa abordagem filosófica. Neste sentido, como auxiliar a discernir, entre tantas possibilidades textuais, aquelas mais apropriadas a uma investigação filosófica coletiva sem, contudo, cair na armadilha da normatividade e prescrição?

Não há como afirmar quais sejam os melhores textos. É possível que mesmo naqueles textos mais triviais, uma abordagem problematizadora e inquietante faça surgir uma discussão rica e aprofundada. Em temas banais e corriqueiros questões intensas podem estar enraizadas. O ponto de partida pode ser mesmo o ocasional, qualquer coisa que se constitua matéria de filosofia, um motivo para a busca do saber.

De modo eventual, algo pode surgir de fora e penetrar o contexto da investigação, alterando assim sua própria forma, extrapolando a situação banal ou circunstancial que o gerou. É como se o fato corriqueiro, banalizado na rápida passagem do diaa-dia, fosse interrompido. E, então, esta parada brusca o suspendesse da ação ordinária, acarretando uma certa tensão entre o que parecia natural e o evento do saber que se interpõe. Embora efêmero, este momento pode se constituir numa rara ocasião para a produção do saber. Aliás, exatamente por ser efêmera e intensa é que esta experiência tende, paradoxalmente, a se prolongar numa temporalidade enigmática, não-linear.

Há, porém, textos que tendem a facilitar uma discussão filosófica por já conterem questões intrigantes. Há também aqueles que não possuem, mas suscitam perguntas problematizadoras exteriores. A carga sugestiva do texto, o que ele nos permite fazer para além dele é uma característica evidenciadora do seu potencial. Quão provocativo o texto é, o quanto nos faz pensar, são critérios seletivos. Poemas, músicas, fotografias, notícias, quadrinhos, dramatizações, pinturas, obras filosóficas clássicas, enfim, qualquer forma textual que nos interpele e nos atravesse provocando nossa curiosidade e espanto e despertando nosso desejo de inquirir e investigar pode ser considerado um bom texto.

Selecionar um texto é elegê-lo entre outros. É escolhê-lo, decidir-se por ele. É algo que nos coloca em movimento e perigo. Arriscamo-nos. Não sabemos, de antemão, se o texto por nós eleito será aceito ou bem recebido. O remetemos e nos colocamos à espreita, aguardando atentamente a co-respondência que nos será enviada por aqueles que os receberam. Não nos cabe antecipar a resposta, a nós alheia. Tampouco podemos nos eximir da responsabilidade pelo que foi enviado. Trata-se de recolhermo-nos um pouco, apenas o bastante para que os outros tenham chance de responder ao nosso apelo. Sim, é angustiante. Afinal, gostaríamos que nosso esforço fosse reconhecido, que nossa escolha fosse acatada, que nossa admiração pelo texto pudesse ser compartilhada. Mas nem sempre é 
assim. Acolher um texto exige disposição e pode ser que os destinatários não tenham disponibilidade. Pode ser ainda que não queiram se entregar ao texto ou mesmo que não permitam que o texto lhes seja entregue. Neste caso, melhor não insistir. A experiência da leitura de qualquer texto é um ato de liberdade, uma relação que alguém estabelece consigo mesmo.

Podemos propiciá-la, mas é impossível realizá-la por outro. É preciso uma abertura do próprio leitor. Entre o leitor e o texto deve haver uma relação interior, uma experiência capaz de transformá-los reciprocamente. Trata-se de um "duplo devir".

Este movimento mútuo também precisa ocorrer da parte de quem envia ou remete o texto. Remeter é meter-se. Colocar-se dentro. Quem remete também se arremessa. Lança-se em direção ao outro. Vai junto ao texto. Inclui-se.

\section{Referências Bibliográficas}

LARROSA, Jorge. Pedagogia Profana. Ed. Autêntica: Belo Horizonte, MG, 2000.

MORAIS, Regis de. A educação do sentimento. Ed. Letras \& Letras: São Paulo, SP, 1999.

(1) Bernardina Maria de Sousa Leal é Mestre em Educação pela Universidade de Brasília, especialista em Administração Escolar pela Universidade Católica de Brasília e graduada em Letras pela Universidade de Brasília. Atualmente coordena as atividades de Pós-Graduação da FASB em Teixeira de Freitas, Bahia, onde também leciona. E-mail: dinaleal2@yahoo.com.br 